Article

\title{
Ergonomics-Based Factors or Criteria for the Evaluation of Sustainable Product Manufacturing
}

\author{
Chiuhsiang Joe Lin ${ }^{1}$, Tariku Tamiru Belis ${ }^{1}$ and Tsai Chi Kuo ${ }^{2, *}$ \\ 1 Department of Industrial Management, National Taiwan University of Science and Technology, Taipei 10607, \\ Taiwan; chiuhsiangjoelin@gmail.com (C.J.L.); tamirutariku@gmail.com (T.T.B.) \\ 2 Department of Industrial and Systems Engineering, Chung Yuan Christian University, Taoyuan 32023, \\ Taiwan \\ * Correspondence: tckuo@cycu.edu.tw
}

Received: 16 August 2019; Accepted: 6 September 2019; Published: 11 September 2019

\begin{abstract}
The issue of sustainability has received substantial attention internationally. It is spreading widely through policy, industry, commerce, research, academia, and other arenas. However, most previous studies on product sustainability were conducted based on a consideration of environmental protection, economic prosperity, and social wellbeing criteria, but there was less representation of specific social wellbeing criteria. The main objective of this study was to formulate well-defined ergonomics-based criteria for product sustainability evaluation and to validate the importance of the identified factors using a fuzzy Delphi method. In this paper, ergonomics-based product sustainability factors are organized by sustainability categories and grouped into employee wellbeing, the economy, and the environment. In the context of manufacturing, evaluating product sustainability from an ergonomics perspective provides more comprehensive social dimension criteria by addressing human characteristics, behavior, performance, human interaction with a product, workplace, working environment, and the product across its life cycle. In addition, a Delphi questionnaire, designed with a nine-point scale, was applied to obtain expert opinions on the importance of each factor; the opinions were combined for each factor by considering the degree of importance assigned to the experts, and the similarities and differences between expert opinions. Finally, high-priority factors were screened from the sustainability categories based on their respective threshold value. Knowing these high-priority factors will help manufacturing industries allocate their resources accordingly for sustainability improvement.
\end{abstract}

Keywords: sustainability; sustainable product manufacturing; social dimension; ergonomics-based factors; fuzzy Delphi method; product life cycle stages

\section{Introduction}

Sustainable development has been receiving substantial attention and has become a concern for researchers as well as practitioners in various areas, such as design, engineering, and business, over the past few decades. It is a concept of development that is widely spreading throughout the world through policy, industry, commerce, research, academia, and other arenas [1]. The three correlated pillars of sustainable development are environmental protection, social wellbeing, and economic prosperity, which are integrated in a framework described as the triple bottom line (TBL) [2-5]. For the achievement of worldwide sustainable development, the United Nations has set 17 sustainable development goals, and countries, manufacturing industries, service providers, and other organizations must consider them over the next 15 years in their long- and short-term planning and implementation activities [6].

According to the definition presented by the World Commission on Environment and Development (WCED) [7], "sustainable development is development that meets the needs of the present without 
compromising the ability of future generations to meet their own needs." This definition contains two key concepts. One is the essential needs of the world's poor, to which priority should be given, and the other is the limitations imposed by the state of technology and social organization on the environment's ability to meet present and future needs [8]. From a manufacturing point of view, the U.S. Department of Commerce defines sustainable manufacturing as the transformation of raw materials into finished products through processes that reduce negative environmental impacts, make optimal use of energy and natural resources, are safe for society, and are economically sound. This has been further explained by the National Council for Advanced Manufacturing (NACFAM), which describes sustainable manufacturing as the manufacturing of sustainable products (product sustainability) and the sustainable manufacturing of all products (process sustainability) [2,5,8-12].

Manufacturing is one of the basic economic activities of a nation, and efforts towards sustainable manufacturing are crucial for the sustainable development of the nation. However, the primary concern of most companies and the manufacturing industry is success on the financial market (i.e., economic prosperity). Because of governmental laws and policies for sustainability in companies and pressure from consumers to employ sustainable production processes, the development of new approaches, processes, applications, and products that also consider environmental protection and social wellbeing are becoming more important for companies [13]. For instance, the UN [6] adopted 17 goals supplemented by specific targets to be achieved for the 2030 Agenda for Sustainable Development. One of these goals encourages companies, especially large-scale companies, to adopt sustainable practices and integrate sustainability into their production planning process. Moreover, in recent times, the manufacturing industry has recognized the need for sustainable growth to withstand the challenges of rapidly depleting natural resources, continuing climate change, increasing environmental pollution, growing customer awareness of the importance of sustainability, and global competition $[4,5]$.

As stated in the explanation of a sustainable products corporation, sustainable products are those that provide environmental, societal, and economic benefits while maintaining employee, consumer, and community health and wellbeing, and the environment over their total life cycle (which includes premanufacturing, manufacturing, use, and post-use) [4]. The manufacture of sustainable products needs to be maintained at a certain level that requires continuous improvement and can be achieved by optimizing the sustainability indicators [14]. Therefore, an overall manufacturing sustainability performance assessment must consider an approach that equally considers the sustainability dimensions (i.e., the economic, environmental, and social dimensions) [15] and implements the $6 \mathrm{R}$ principles (reduce, re-manufacture, reuse, recycle, redesign, and recover) throughout the total life cycle of the products $[4,5,8]$.

However, researchers agree that, ideally, the equal consideration of the triple bottom line is required for overall better achievement of organizational sustainability. They mostly focus on economic and environmental sustainability rather than social sustainability; that is, they focus separately on the environmental criteria, or on both economic and environmental criteria, or on the three pillars with less detail and too generally on the social dimension indicators. [16-20]. This indicates that there is less representation of the social dimensions in previous studies related to manufacturing sustainability performance evaluations. For instance, Sutherland, et al. [18] state that the social pillars of sustainability are influenced by the identification of manufacturing sustainability social indicators and frameworks throughout the upstream and downstream manufacturing supply chains to account for the social consequences of a company's activities, presenting a promising direction for research related to manufacturing. Research gaps on the social dimension criteria and indicators for product sustainability evaluation exist.

Products produced in manufacturing have direct and indirect interactions with society (employees, company owners, the community, and customers) throughout their life cycles. Therefore, it is necessary to optimize the impacts of the products on society. For this to be achieved, different disciplines, such as sustainability, engineering, design, manufacturing, and ergonomics, could play important roles. As reviewed by Radjiyev et al. [21], ergonomics could play an important role in supporting 
the transition to sustainable development because both ergonomics and sustainable development are human-centered. Although ergonomics or human factors are by their very nature concerned with an understanding of the interactions among humans and other elements of a system to optimize human wellbeing (i.e., the social goal) and overall system performance (i.e., the economic goal), which directly achieve sustainability outcomes, there is a lack of clear reported or published contributions from ergonomics to sustainable development, indicating that few ergonomists are solving or addressing sustainability issues [1,21-23].

To bridge this gap, the main objective of this research is to develop a comprehensive set of ergonomics-based factors or criteria and a framework of sustainable product manufacturing that considers the total life cycle of the product, while also identifying key criteria of product sustainability from the established set. This study is intended to improve the representation of the social dimensions in performance evaluations of the manufacturing of sustainable products and to provide ways of identifying the relatively important criteria and factors of product sustainability through the following specific objectives:

- Investigate and identify a list of ergonomic-based factors/criteria of sustainable product manufacturing from the literature by considering the interaction of the product with society in the stages of premanufacturing, manufacturing, use, and post-use. From the perspective of manufacturing, identifying criteria/factors and evaluating product sustainability from an ergonomics perspective will provide a more comprehensive social dimension criteria by addressing human characteristics, behavior, performance, human interaction with the workplace, the working environment, and a product across its life cycle [1].

- Design a questionnaire based on the identified list of ergonomics-based factors of sustainable product manufacturing so as to collect the opinions of experts on the levels of importance of the factors.

- Apply a fuzzy Delphi method that considers the similarities and differences between the opinions of experts to reach a consensus on the relative importance of the factors and determine those that can be used in further research to evaluate the performance of sustainable product manufacturing.

\section{Theoretical Background}

\subsection{Some Related Previous Works}

Nowadays, manufacturers are obliged to meet customer expectations in terms of sustainable products and comply with governmental rules and regulations on sustainable manufacturing. Because of this, many of them are focusing on achieving sustainability in every possible aspect of the total life cycle of the products [12,24]. According to Fiksel et al. [25], providing a thorough and quantitative sustainability assessment of a specific product is a challenging and complex task for concerned researchers. Therefore, such researchers have focused on identifying indicators and developing sustainability frameworks and methodologies for evaluating manufacturing product sustainability. This section presents some related previous works on the sustainability of specified manufacturing products.

Cao et al. [17] presented a sustainability assessment considering only the social dimension of sustainability factors on the basis of ergonomics. That study classified a social sustainability framework into sustainability aspects (i.e., work task, work environment and human-machine interaction) and the indicators that measure sustainability aspects. The researchers also designed a fuzzy inference system (FIS) to obtain a social sustainability score, which is further converted into a social sustainability index.

Shuaib et al. [4] presented a product sustainability index methodology and its application by considering the three sustainability dimensions, or the triple bottom line. That study divided the sustainability assessment methodology into sub-indices (i.e., economy, environment, and society), clusters, subclusters, and individual metrics. This methodology covers the total product life cycle (i.e., premanufacturing, manufacturing, use, and post-use) and the sustainability factors by considering the 
6Rs (i.e., recycle, reuse, redesign, recover, remanufacture, and reduce). Additionally, the researchers proposed a methodology used to determine the overall product sustainability assessment through a series of steps, including individual metrics measurement and data collection, data normalization, weighting, and aggregation. Finally, they demonstrated the application of their developed methodology in a case study on sustainability evaluation and comparison of two generations of consumer electronic products.

Schuch Bork et al. [26] presented a methodological tool to measure the sustainability performance of products and processes. The method is based on process variables, which are designated according to individual metrics and expected to have impacts on the technological, environmental, social, and economic aspects. The researchers also include evaluation scores for the importance of variables, data normalization, and aggregation of variable scores based on the sustainability dimension group. The representation of variables used to evaluate the impact on the social aspect is less than that of the other two dimensions of sustainability.

Singh et al. [27] proposed a model based on a fuzzy inference system for the evaluation of the manufacturing sustainability of small and medium enterprises. Their evaluation includes sustainability variables identified according to the characteristics of the enterprises and categorized under environmental, economic, and social dimensions. For the accomplishment of the evaluation process, the researchers utilized the data collected from decision-makers' opinions on the importance of sustainability variables using linguistic variables. However, in that study, of the three dimensions of sustainability, the environmental dimension received a disproportionately large amount of the emphasis.

As can be seen from the literature review above, most of the studies to date have considered the idea of the triple bottom line for identifying sustainability indicators and developing a framework and methods for the sustainability assessment; however, they have not considered the three dimensions equally. In addition, the majority of the studies used identified factors/criteria without validating their relative importance using experts' or decision-makers' opinions. This study focused on the development of ergonomics-based sustainability criteria for manufacturing industries based on the triple bottom line (TBL) and considering a product's characteristics throughout its life cycle. Additionally, this paper provides a screening mechanism for identifying the key important criteria from the identified list.

\subsection{Sustainable Products Manufacturing}

Manufacturing is the process of producing goods or products from raw materials in a large number in industries. It is the source of all the goods for living, transportation, entertainment, production, safety, and health [10]. Therefore, the products manufactured by industries must have optimized negative and positive impacts on society, the environment, and the economy, or they should be sustainable products. Sustainable product manufacturing is an important issue to achieve sustainable development.

According to the Lowell Center for Sustainable Production (LCSP), sustainable products manufacturing is defined as the transformation of raw materials into final products using processes that do not affect the environment while saving energy and other resources, being economically feasible, and assuring the safety and wellbeing of society [28]. In a similar approach, a sustainable products corporation defined sustainable products as those realizing environmental, societal, and economic benefits while protecting the health and wellbeing of society and the environment over their entire life cycle [4]. This study investigates the direct and indirect effects of a product on society (i.e., employees, customers, and the community) in the total product life cycle (i.e., premanufacturing, manufacturing, use, and post-use) from an ergonomics perspective so as to achieve sustainable products (Figures 1 and 2). 


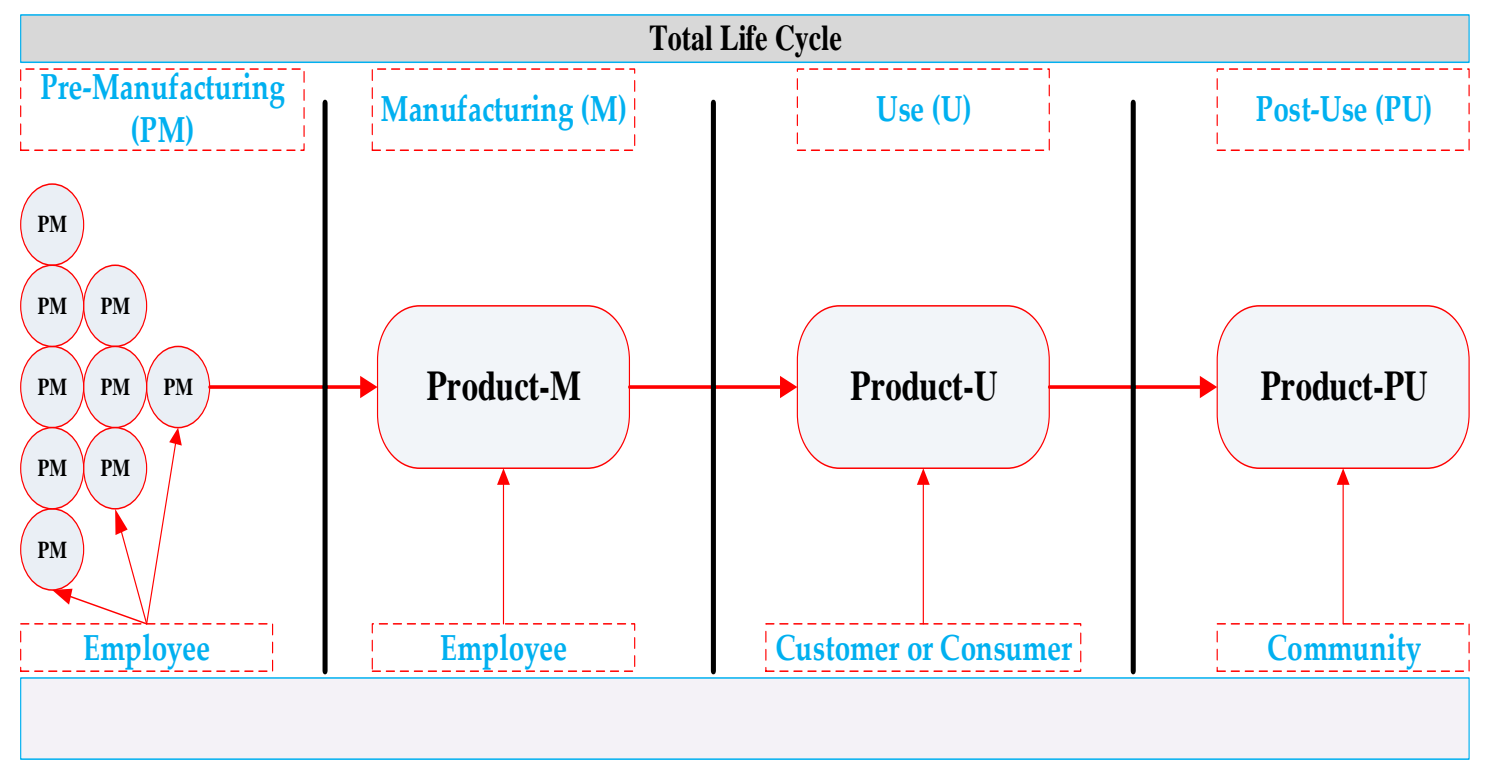

Figure 1. Total product life cycle stages.

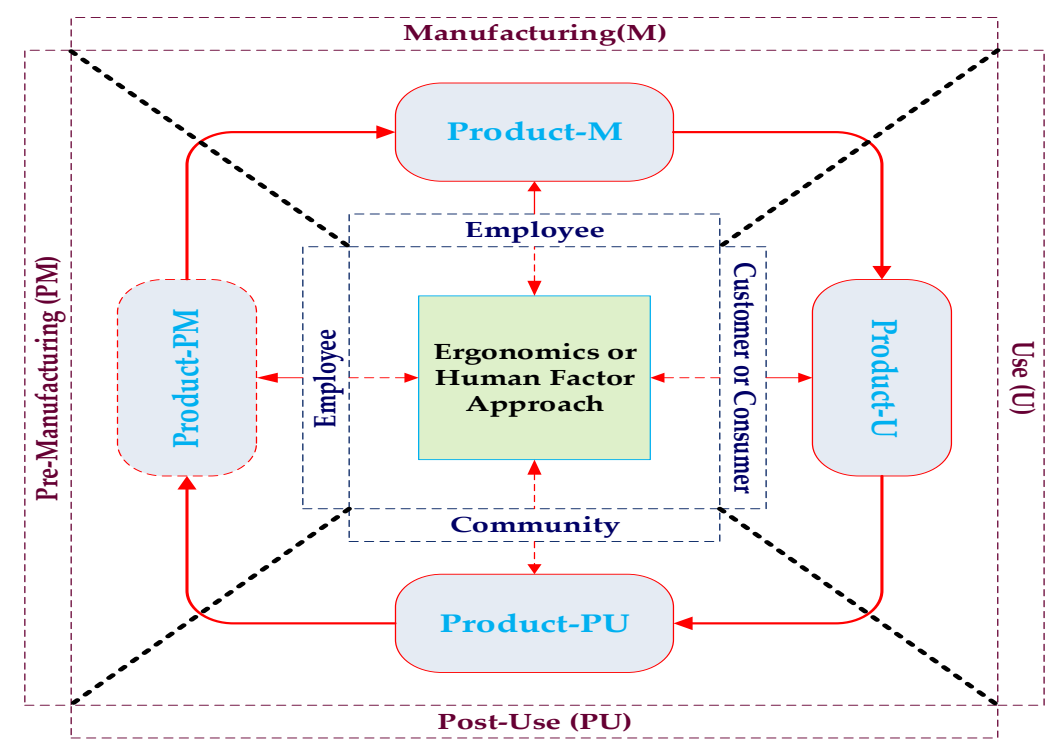

Figure 2. The interaction between society (employees, customers, and society) and the product life cycle stages.

\subsection{Sustainability Dimensions and Factors or Indicators}

\subsubsection{Sustainability Dimension}

Organizations working towards sustainable development, including the United Nations, state that sustainable development requires appropriate consideration of economic, environmental, and social aspects at the same time. This idea guides the three pillars of sustainability, called the triple bottom line, according to Elkington [29]. Elkington considers sustainability as overlapping circles of three-dimensional relationships among economic, environmental, and social aspects, in which achievement of at least a basic level of these aspects is a basis for overall sustainability.

Another way of representing the interrelationships of the triple bottom line is concentric spheres, which represent the economic and social spheres as being dependent on the wellbeing of the environmental aspect [30]. 
From a manufacturing point of view, this study defines the product sustainability dimensions (i.e., social, economic, and environmental) from the perspective of ergonomics or human factors as follows: The social dimension (which the study called employee-centered products) contains issues directly related to satisfying the requirements of society (i.e., employees at the premanufacturing and manufacturing stages). This aspect includes the factors affecting employee health, wellbeing, and performance and also transparency about the production process in terms of simplicity of production and maintenance. The economic aspect (which the study calls user-centered and resource efficient products) directly and indirectly benefits society and stakeholders by optimizing the production and resource utilization. The environmental aspect (which this study calls the end-of-life of a product) is the consideration of the direct influence of the product after its use and its consequences to the community.

\subsubsection{Sustainability Factors or Indicators}

Indicators can be defined to describe the status of a system. Sustainability indicators are a significant way of measuring and assessing sustainability [31]. Manufacturing sustainability indicators/factors are used to describe the status of manufacturing in terms of sustainability performance. However, there exist several sources for organizational sustainability indicators, such as the Global Report Initiative (GRI), Dow Jones Sustainability Index (DJSI), Environmental Sustainability Indicators (ESI), and United Nations Indicators of Sustainable Development (UN-CSD) [32,33]. This study develops ergonomics-based factors/indicators of sustainable product manufacturing. The identified factors are adopted from the ergonomics/human factor concept by addressing human characteristics, behavior, performance, human interaction with the workplace, the working environment, and the product across its life cycle, considering the basic principles of the source of sustainable development.

\section{Ergonomics-Based Factors or Indicators of a Manufacturing Product Sustainability Framework}

Manufacturing sustainability is an issue that has attracted worldwide attention. As described in the literature review, researchers, organizations, and other concerned bodies agree that the assessment of the sustainability levels of manufacturing industries requires a consideration of the appropriate proportions of factors/indicators under the three pillars of sustainability. However, the majority of previous studies on manufacturing product sustainability have placed a greater emphasis on factors/indicators of the environmental and economic dimensions than on those of the social dimensions [16-19]. To overcome the challenges of manufacturing industries regarding sustainability, different disciplines, including ergonomics or human factors, are directly involved. Although ergonomics could play an important role in the transition of sustainable development (because both ergonomics and sustainability are human-centered and concerned with the optimization of social, economic, and environmental benefits), there has recently been an insufficient direct connection made with sustainable development [1,21].

To fill the research gap related to the social dimension and to show the role of ergonomics in sustainable product manufacturing, this study is concerned with identifying the list of ergonomics-based factors/indicators of manufacturing product sustainability. In this process, the concept of $6 \mathrm{R}$ (reduce, recycle, remanufacture, reuse, recover, and redesign) is considered throughout the product life cycle (premanufacturing, manufacturing, use, and post-use) (Figures 1 and 2).

This study provides a more comprehensive social dimension by addressing human characteristics, behavior, performance, and human interaction with other elements of product manufacturing systems throughout the product life cycle. In this context, the term human refers to employees at the premanufacturing and manufacturing product stages, customers at the use stage, and the community at the post-use stage. The sustainable product manufacturing framework includes four stages. Stage 1 is the main objective, which is ergonomics-based sustainability performance or value. Stage 2 is the sustainability dimension or pillars, including social (employee-centered products), economic (user-centered and resource efficient products), and environmental (end-of-life of the products). Stage 3 is the categories under each dimension, consisting of occupational safety and health, simplicity of production and maintenance, employee performance, user-centered products, resource-efficient 
products, valuable resources, waste, and emissions. Stage 4 is a list of factors or criteria for sustainable product manufacturing (Figure 3).

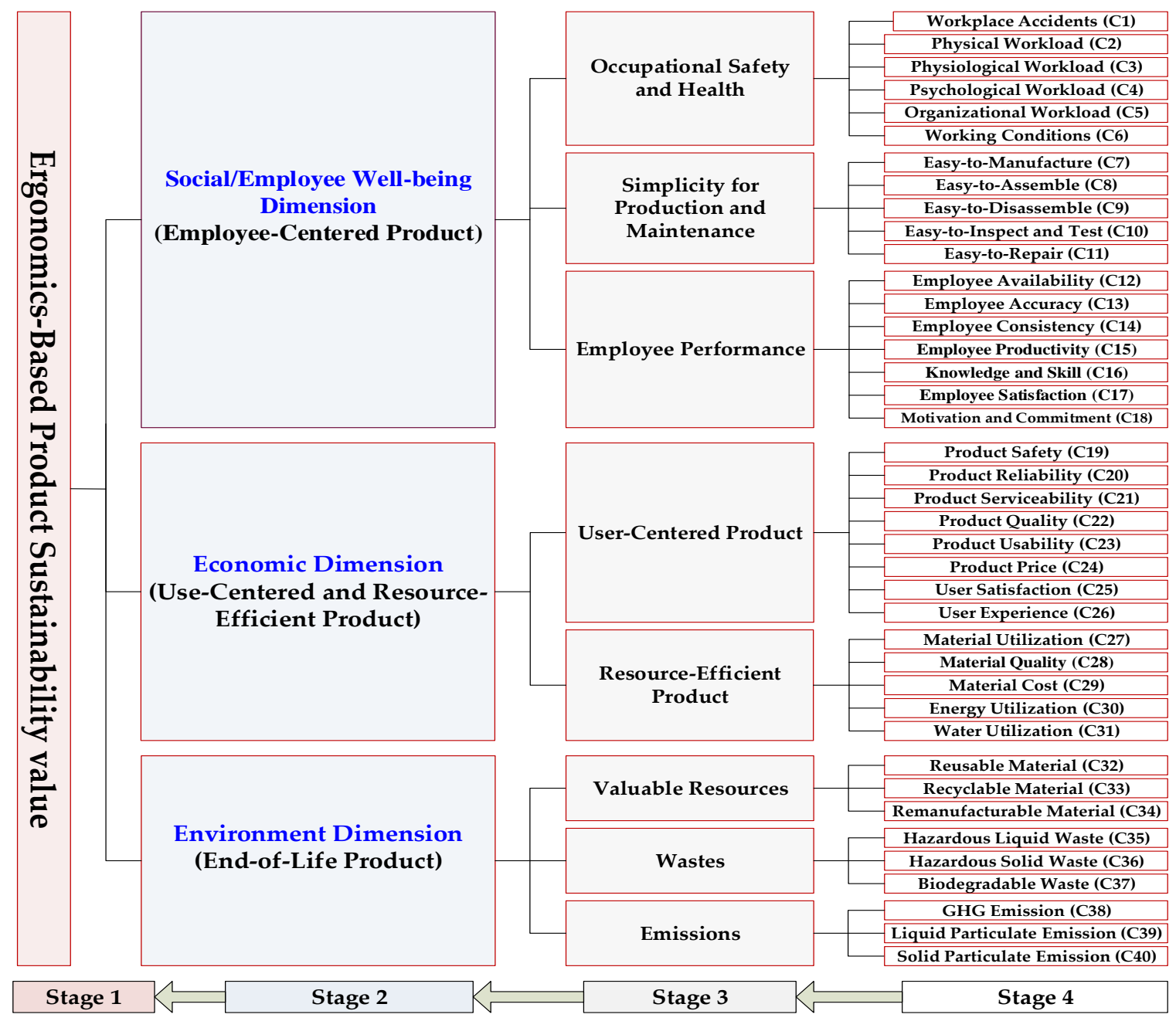

Figure 3. Hierarchical framework of ergonomics-based factors or criteria of sustainable product manufacturing.

The factors or criteria developed or identified have positive or negative impacts on the employees, customers, community, and other stakeholders. For example, in stage 1, workplace accidents are one of the factors under occupational safety and health, which are identified to investigate the manufacturing industry performance regarding accidents, incidents, and injuries to the employees at the workplace while producing the product. In stage 2, user satisfaction is a factor under user-centered products; it is selected to determine the status of the manufacturing industries on how well users or customers are satisfied with the product. In stage 3, the hazardous liquid waste factor is taken into consideration with the intention of evaluating the amount of nonbiodegradable hazardous waste from the end-of-life of a product that remains in liquid form to understand its impact on the community. The operational or working definitions of all factors are listed in Table 1. 
Table 1. Operational or working definitions of ergonomics-based factors/criteria for sustainable product manufacturing.

\begin{tabular}{|c|c|c|}
\hline Sustainability Category & Factor or Criteria & Short Operational Definition \\
\hline \multirow{6}{*}{ Occupational Safety and Heath } & Workplace Accidents & Accidents, incidents, injuries involving employees at the workplace while producing the product \\
\hline & Physical Workload & Excessive force, awkward posture, repetitive task, contact stress \\
\hline & Physiological Workload & Metabolic energy expenditure, oxygen consumption, heart rate, respiration rate \\
\hline & Psychological Workload & Mental stress, fatigue, depression, dissatisfaction, emotion, demotivation \\
\hline & Organizational Workload & Rules and regulations, benefits and premises, work/rest schedule, communication, bureaucracy \\
\hline & Working Conditions & Exposure to temperature, humidity, pollution, noise, vibration, light, hazardous substances/materials \\
\hline \multirow{5}{*}{ Simplicity of Production and Maintenance } & Easy-to-Manufacture & Describes how simple it is for the employee to manufacture a product \\
\hline & Easy-to-Assemble & Refers to how simple it is for the employee to assemble a product \\
\hline & Easy-to-Disassemble & Explains how simple it is for the employee to disassemble a product \\
\hline & Easy-to-Inspect and -Test & Describes how simple it is for the employee to inspect and test a product \\
\hline & Easy-to-Repair & States how simple it is for the employee to repair a product \\
\hline \multirow{7}{*}{ Employee Performance } & Employee Availability & Amount of time that employees spend at their workplace to produce the product \\
\hline & Employee Accuracy & Refers to how well employees can perform their tasks \\
\hline & Employee Consistency & Describes how well employees perform their tasks every time \\
\hline & Employee Productivity & Effective and efficient utilization of employee-hours for producing the product \\
\hline & Knowledge and Skill & Describes how well an employee is able to perform a task \\
\hline & Employee Satisfaction & States how satisfied an employee is with the job \\
\hline & Motivation and Commitment & Explains how much an employee is committed to performing a task \\
\hline \multirow{8}{*}{ User-Centered Product } & Product Safety & Describes how a product causes no damage or loss to the user \\
\hline & Product Reliability & Ability to function without failure for the intended period of time \\
\hline & Product Serviceability & Refers to how easy it is for the user to repair a product \\
\hline & Product Quality & Meeting the user's requirements or specifications \\
\hline & Product Usability & Describes how easy the product is to use \\
\hline & Product Price & Refers to how reasonable the price of the product is to users \\
\hline & User Satisfaction & Describes how satisfied a user is with the product \\
\hline & User Experience & Explains how satisfied a user is with the product \\
\hline \multirow{5}{*}{ Resource-Efficient Product } & Material Utilization & Amount of materials (i.e., product materials and packaging materials) used to produce the product \\
\hline & Material Quality & Meeting manufacturer's requirements or specifications \\
\hline & Material Cost & Reasonable price of the input materials to the manufacturer \\
\hline & Energy Utilization & Amount of energy (thermal, electricity) consumed to produce the product \\
\hline & Water Utilization & Amount of water consumed to produce the product \\
\hline \multirow{3}{*}{ Valuable Resources } & Reusable Material & Amount of end-of-life of product's components, subassemblies of product used after its first life cycle in subsequent life cycles \\
\hline & Recyclable Material & Amount of converted end-of-life of product's components, subassemblies into new materials to be used in new products \\
\hline & Re-manufacturability of Material & $\begin{array}{l}\text { Amount of reprocessed end-of-life of product's components, subassemblies or the product itself for restoration to their original } \\
\text { state to perform a similar or improved functionality }\end{array}$ \\
\hline \multirow{3}{*}{ Waste } & Hazardous Liquid Waste & Amount of non-biodegradable hazardous waste from end-of-life of product remaining in liquid form \\
\hline & Hazardous Solid Waste & Amount of non-biodegradable hazardous waste from end-of-life of product remaining in solid form \\
\hline & Biodegradable Waste & $\begin{array}{l}\text { Amount of end-of-life of product organic material (including packing materials) decomposed into compost and biogas by } \\
\text { microorganisms and exposure to heat }\end{array}$ \\
\hline \multirow{3}{*}{ Emissions } & GHG Emission & Amount of greenhouse gases (GHG) emitted from the end-of-life of product materials to the environment \\
\hline & Liquid Particulate Emission & Amount of liquid particulate emitted from the end-of-life of product materials \\
\hline & Solid Particulate Emission & Amount of solid particulate emitted from the end-of-life of product \\
\hline
\end{tabular}




\section{Methodology}

\subsection{Data Collection and Methods of Analysis}

The development of relatively important factors or criteria for sustainable product manufacturing requires the involvement of expert or manager opinions. This human judgement generates high degrees of uncertainty and subjectivity. This study employed data obtained from an expert-based questionnaire survey. The questionnaire was prepared from 40 ergonomics-based factors/criteria of sustainable product manufacturing identified in the framework (Figure 3). A total of 41 experts (i.e., professors, research fellows, experts/designers and managers/executives) were contacted by e-mail to participate in the survey. Of the 41 people contacted, 35 experts properly completed the questionnaire; the response rate was $85.36 \%$. Respondents' information (i.e., position/title, qualification, experience and employer), objectives, and a short description of the study and questionnaire items with proper definitions and decision alternatives were included in the survey questionnaire. The survey asked the participants to rate the levels of significance of each of the ergonomics-based factors/criteria in manufacturing product sustainability on a nine-point Likert-type scale with their respective linguistic terms. The study utilized two types of linguistic variables, and according to the rating values of the linguistic terms, the opinions of experts were transformed into their equivalent fuzzy numbers, as presented in Table 2 [34].

Table 2. Linguistic variables with their corresponding linguistic values of triangular fuzzy numbers.

\begin{tabular}{llc}
\hline \multicolumn{1}{c}{ Linguistic Variables } & \multicolumn{1}{c}{ Linguistic Variables } & $\begin{array}{c}\text { Triangular Fuzzy Numbers } \\
\text { (TFNs) }\end{array}$ \\
\hline Low importance (LI) & Low effect (LE) & $(0.0,0.0,0.125)$ \\
Intermediate between LI and MI & Intermediate between LE and ME & $(0.0,0.125,0.25)$ \\
Moderate importance (MI) & Moderate effect (ME) & $(0.125,0.25,0.375)$ \\
Intermediate between MI and SI & Intermediate between ME and SE & $(0.25,0.375,0.5)$ \\
Strong importance (SI) & Strong effect (SE) & $(0.375,0.5,0.625)$ \\
Intermediate between SI and DI & Intermediate between SE and DE & $(0.5,0.625,0.75)$ \\
Demonstrated importance (DI) & Demonstrated effect (DE) & $(0.625,0.75,0.875)$ \\
Intermediate between DI and EI & Intermediate between DE and EE & $(0.75,0.875,1.0)$ \\
Extreme importance (EI) & Extreme effect (EE) & $(0.875,1.0,1.0)$ \\
\hline
\end{tabular}

Sustainability factors/criteria (qualitative/quantitative) identification and assessment problems are usually difficult to manage due to the presence of complexity along with a series of uncertainties and vagueness [35]. To overcome these challenges, this study utilized a fuzzy approach by considering expert opinions in the form of linguistic variables. In a fuzzy concept based on the shape or nature of the fuzzy membership function, fuzzy numbers are classified as trapezoidal, Gaussian and triangular. Because they are intuitive, easily applicable, and useful in promoting representation and information processing in a fuzzy environment [36], this study applied linguistic variables with their respective triangular fuzzy numbers, as represented in Figure 4.

The data obtained from the questionnaire survey in the form of linguistic variables were used as the input for the decision process on the relative importance of the identified ergonomic-based factors or criteria of sustainable product manufacturing. To accomplish this decision, we applied the fuzzy Delphi method, which is used for screening processes in disciplines such as engineering, management, business and the physical sciences [37]. The comprehensive procedural approach of the study is represented in Figure 5. 


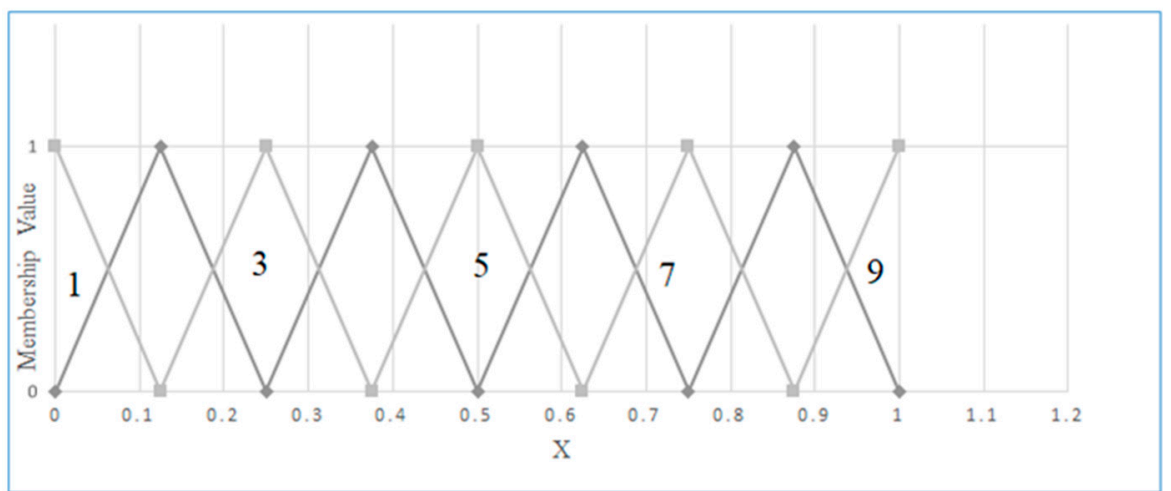

Figure 4. Triangular membership function of linguistic variable for importance or effect. 1 : Low; 3 : Moderate; 5: Strong; 7: Demonstrated; 9: Extreme.

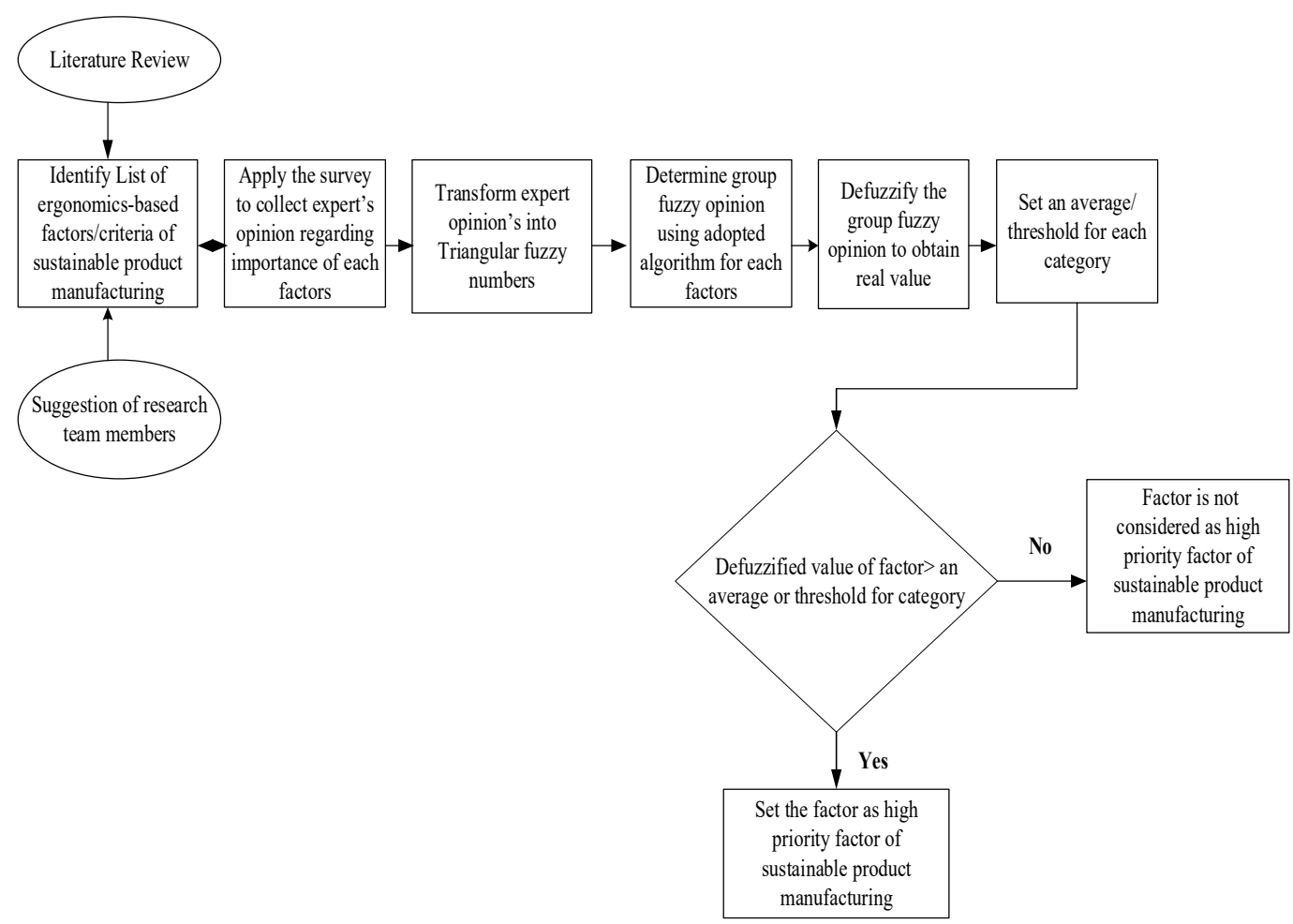

Figure 5. Flowchart of fuzzy Delphi method to screen the relative importance of the factors of ergonomics-based sustainable product manufacturing.

The aggregation of expert opinions for a single factor can be obtained based either on similarity, in which the consistency of each expert with the others is considered, or on the differences between experts' opinions [38,39]. Considering either of them separately will lead to a loss of information and make a decision on the factor incomplete. Therefore, this study utilized the similarity- and difference-based approaches equally to determine the group consensus on the importance level of each of the factors/criteria of ergonomics-based sustainable product manufacturing through the following adopted algorithm.

Step 1: Arrange the opinions of all experts (total number of experts: 35 ) on each questionnaire item (i.e., factors/criteria) in the form of triangular fuzzy numbers, which are the minimum (a), optimum (b) and maximum (c):

$$
\text { i.e., } E O_{i}=\left(a_{i}, b_{i}, c_{i}\right) \text { for }, i=1,2, \ldots, n
$$

where $n$ is the total number of experts in the study and $E O_{i}$ is the $i^{\text {th }}$ expert opinion. 
Step 2: Determine the similarity $S\left(E O_{i}, E O_{j}\right)$ among each pair of experts' opinions $E O_{i}=\left(a_{i}, b_{i}, c_{i}\right)$ and $E O_{j}=\left(a_{j}, b_{j}, c_{j}\right)$ for all participants, using [40]

$$
S\left(E O_{i}, E O_{j}\right)=1-\left[\frac{\left(/ a_{i}-a_{j} /+/ b_{i}-b_{j} /+/ c_{i}-c_{j} /\right)}{3}\right]
$$

For $i=j, S\left(E O_{i}, E O_{j}\right)=1$, and $S\left(E O_{i}, E O_{j}\right)=S\left(E O_{j}, E O_{i}\right)$.

Step 3: Calculate the distance difference $d\left(E O_{i}, E O_{j}\right)$ between each pair of experts' opinions $E O_{i}=\left(a_{i}, b_{i}, c_{i}\right)$ and $E O_{j}=\left(a_{j}, b_{j}, c_{j}\right)$ for the total number of experts using the formula of distance difference between two triangular fuzzy numbers [41]:

$$
D\left(E O_{i}, E O_{j}\right)=\frac{1}{2}\left\{\max \left(/ a_{i}-a_{j} /, / c_{i}-c_{j} /\right)+/ b_{i}-b_{j} /\right\} .
$$

Then transform the distance into a normalized distance differences using:

$$
d\left(E O_{i}, E O_{j}\right)=D\left(E O_{i}, E O_{j}\right) / \max _{i, j} D\left(E O_{i}, E O_{j}\right)
$$

For $i=j, d\left(E O_{i}, E O_{j}\right)=0$, and $d\left(E O_{i}, E O_{j}\right)=d\left(E O_{j}, E O_{i}\right)$.

Step 4: Calculate the consistency degree $r\left(E O_{i}, E O_{j}\right)$ between each pair of experts' opinions for $i, j=1,2, \ldots, n[42]$

$$
r\left(E O_{i}, E O_{j}\right)=\alpha S\left(E O_{i}, E O_{j}\right)+(1-\alpha)\left[1-d\left(E O_{i}, E O_{j}\right)\right]
$$

For this study, the equal importance of similarity and difference among the experts was indicated by the value of $\alpha$ being 0.5 .

Step 5: Calculate the degree of importance of each expert based on their years of experience. In this study, the years of experience of the participants in the survey were categorized as follows:

\begin{tabular}{|c|c|c|c|c|c|c|c|c|}
\hline Expert & $\mathrm{E}_{1}$ & $\mathrm{E}_{2}$ & $\mathrm{E}_{3}$ & $\mathrm{E}_{4}$ & $\mathrm{E}_{5}$ & $\mathrm{E}_{6}$ & $\mathrm{E}_{7}$ & $\mathrm{E}_{8}$ \\
\hline Value of Expert & 5 & 1 & 1 & 5 & 5 & 2 & 2 & 1 \\
\hline Expert Relative Importance & 0.0495 & 0.0099 & 0.0099 & 0.0495 & 0.0495 & 0.0198 & 0.0198 & 0.0099 \\
\hline Expert & E9 & $\mathrm{E}_{10}$ & $E_{11}$ & $E_{12}$ & $E_{13}$ & $E_{14}$ & $\mathrm{E}_{15}$ & $E_{16}$ \\
\hline Value of Expert & 1 & 2 & 3 & 2 & 2 & 1 & 1 & 3 \\
\hline Expert Relative Importance & 0.0099 & 0.0198 & 0.0297 & 0.0198 & 0.0198 & 0.0099 & 0.0099 & 0.0297 \\
\hline Expert & $\mathrm{E}_{17}$ & $\mathrm{E}_{18}$ & $\mathrm{E}_{19}$ & $\mathrm{E}_{20}$ & $E_{21}$ & $E_{22}$ & $E_{23}$ & $E_{24}$ \\
\hline Value of Expert & 2 & 5 & 1 & 4 & 2 & 5 & 2 & 5 \\
\hline Expert Relative Importance & 0.0198 & 0.0495 & 0.0099 & 0.0396 & 0.0198 & 0.0495 & 0.0198 & 0.0495 \\
\hline Expert & $E_{25}$ & $\mathrm{E}_{26}$ & $\mathrm{E}_{27}$ & $\mathrm{E}_{28}$ & $E_{29}$ & $\mathrm{E}_{30}$ & $E_{31}$ & $\mathrm{E}_{32}$ \\
\hline Value of Expert & 4 & 5 & 1 & 2 & 4 & 5 & 5 & 2 \\
\hline Expert Relative Importance & 0.0396 & 0.0495 & 0.0099 & 0.0198 & 0.0396 & 0.0495 & 0.0495 & 0.0198 \\
\hline Expert & $E_{33}$ & $E_{34}$ & $E_{35}$ & & & & & \\
\hline Value of Expert & 2 & 4 & 4 & & & & & \\
\hline Expert Relative Importance & 0.0198 & 0.0396 & 0.0396 & & & & & \\
\hline
\end{tabular}
below 5 years, $5-10$ years, 10-15 years, $15-20$ years, and above 20 years. The degree of importance $\left(e_{i}\right)$ for each expert is shown in Table 3.

Table 3. Degrees of importance of experts participating in the survey.

Step 6: Calculate the weighted consistency degree $C\left(E_{i}\right)$ for each expert $E_{i}$ for $i, j=1,2, \ldots, n$ by:

$$
C\left(E_{i}\right)=\sum_{j=1}^{n} r\left(E O_{i}, E O_{j}\right) e_{j} .
$$


Step 7: Calculate the aggregation weight $w\left(E_{i}\right)$ of expert $E_{i}$ for $i, j=1,2, \ldots, n$ using the formula below:

$$
w\left(E_{i}\right)=\frac{C\left(E_{i}\right)}{\sum_{j=1}^{n} C\left(E_{j}\right)} .
$$

Step 8: Aggregate each fuzzy opinion for each Factor or indicator 'I' into a group fuzzy opinion $\bar{R}_{I}$ using the formula stated below [42,43]:

$$
\bar{R}_{I}=\sum_{i=1}^{n} w\left(E_{i}\right)(.) E O_{i}
$$

which means:

$$
\begin{gathered}
\bar{R}_{I}=\left\{\left(w\left(E_{1}\right) a_{1}+w\left(E_{2}\right) a_{2}+\ldots+w\left(E_{n}\right) a_{n}\right),\left(w\left(E_{1}\right) b_{1}+w\left(E_{2}\right) b_{2}+\ldots+w\left(E_{n}\right) b_{n}\right),\left(w\left(E_{1}\right) c_{1}+w\left(E_{2}\right) c_{2}+\ldots+w\left(E_{n}\right) c_{n}\right)\right\} \\
\bar{R}_{I}=\left(a_{I}, b_{I}, c_{I}\right) \text { For, } I=1,2, \ldots, 40
\end{gathered}
$$

Step 9: Transform the fuzzy group opinion value of each of the ergonomics-based factors of sustainable product manufacturing into crisp/real values (i.e., defuzzification) using the center of gravity method:

$$
\text { Defuzzified }=\frac{\left(a_{I}+b_{I}+c_{I}\right)}{3} \text {. }
$$

Step 10: Calculate the average or threshold value for each sustainability category using the defuzzified values of the factors in the category. The result will be used to rate the relative importance of factors, in which factors with defuzzified values greater than each separately set average value will be given priority in the improvement of sustainable product manufacturing practice.

\subsection{Reliability of Questionnaire Items}

Reliability is the consistency or repeatability of a measure. Testing the reliability of a questionnaire requires assessment of the relevance and the respondents' understanding of the items on the questionnaire [44]. The internal consistency or reliability is commonly measured with Cronbach's alpha. Therefore, to understand whether the questions in the questionnaire all reliably measured product manufacturing sustainability, in this study, Cronbach's alpha was calculated for the sample of 35 experts in SPSS software (version 20). The Cronbach's alpha was 0.980, which is higher than the minimum acceptable value (0.7).

\section{Results and Discussion}

\subsection{Results}

The comprehensive identification and assessment methods for factors in sustainable product manufacturing requires proper incorporation of the three issues related to product sustainability (i.e., triple bottom line, total life cycle of product, and 6R). However, past reports from researchers, organizations, and other concerned bodies on the issue have been based on their own designed scopes and objectives. In addition, different disciplines can view the sustainability issue in their own dimensions, despite having the same main goal of transition to sustainable development. Our study identified the ergonomics-based factors of sustainable product manufacturing that improve, directly or indirectly, the social aspect factors by considering human characteristics, behavior, performance, human interaction with the workplace, the working environment, and product life cycle. In addition, the relative importance of the factors was determined using the data analysis of questionnaires completed by experts. 
In total, 40 factors of sustainable product manufacturing were identified from the ergonomics/ human factor perspective, considering the positive and negative impacts of products across their life cycles on human (i.e., employee, customer, and community) health, wellbeing, motivation, economics, and skill development. These factors were qualitatively and quantitatively measured in further consideration of the manufacturing sustainability performance evaluation process. To validate the importance of factors for the specified issue and to understand their relative importance, this study utilized an expert-based judgment method (the fuzzy Delphi method). An algorithm that combines the aggregation of similarity- and difference-based expert opinions into a group consensus was applied in the analysis. The analysis was performed in MATLAB R2018 (MathWorks, Natick, MA, USA) software. For each questionnaire item (factor), the fuzzy group consensus values (i.e., minimum, optimum, and maximum) and respective defuzzified values (real values) were determined (Table 4). According to the results, 24 factors (i.e., factors with defuzzified values higher than the average values of their respective categories) were selected as those that require priority in the improvement of sustainable product manufacturing practice.

The results of the analysis showed that the group consensus or defuzzified values corresponding to all ergonomics-based factors of product manufacturing sustainability were between 0.625 and 0.875 (Table 4). These results showed that all identified factors had an appropriate importance or effect on the evaluation of the performance of product sustainability. However, the effects or importance levels of these factors on the sustainability issue are different. To evaluate the importance of each factor, this study considered the threshold value calculated separately for each sustainability category based on the average of the defuzzified values of their factors or criteria. Therefore, those factors with defuzzified values greater than their respective threshold values were considered high-priority factors (Table 4). The detailed description of the relative importance of the factors is presented in Figure 6 according to their respective categories (as shown in Figure 4). 
Table 4. Combined group opinions of ergonomics-based factors of product manufacturing sustainability.

\begin{tabular}{|c|c|c|c|c|c|c|c|}
\hline \multirow{2}{*}{ Category } & \multirow{2}{*}{ Criteria No. } & \multirow{2}{*}{ Factor/Criteria } & \multicolumn{3}{|c|}{ Group Fuzzy Opinion } & \multirow{2}{*}{ Defuzzified Value } & \multirow{2}{*}{ Selected for Priorit } \\
\hline & & & Minimum & Optimum & Maximum & & \\
\hline \multirow{6}{*}{ Occupational Safety and Health } & $\mathrm{C} 1$ & Workplace Accidents & 0.669 & 0.7916 & 0.8745 & 0.7784 & Yes \\
\hline & $\mathrm{C} 2$ & Physical Workload & 0.6161 & 0.7398 & 0.8472 & 0.7344 & - \\
\hline & $\mathrm{C} 3$ & Physiological Workload & 0.6427 & 0.7665 & 0.8737 & 0.7610 & Yes \\
\hline & $\mathrm{C} 4$ & Psychological Workload & 0.6615 & 0.7854 & 0.8818 & 0.7762 & Yes \\
\hline & $\mathrm{C} 5$ & Organizational Workload & 0.6055 & 0.7278 & 0.84 & 0.7244 & \\
\hline & $\mathrm{C} 6$ & Working Conditions & 0.6635 & 0.7875 & 0.8833 & 0.7781 & Yes \\
\hline \multirow{5}{*}{ Simplicity of Production and Maintenance } & $\mathrm{C} 7$ & Easy-to-Manufacture & 0.6009 & 0.7209 & 0.8198 & 0.7139 & Yes \\
\hline & C8 & Easy-to-Assemble & 0.6008 & 0.721 & 0.8238 & 0.7152 & Yes \\
\hline & C9 & Easy-to-Disassemble & 0.5209 & 0.64 & 0.7521 & 0.6377 & - \\
\hline & C10 & Easy-to-Inspect and -Test & 0.6122 & 0.7323 & 0.831 & 0.7252 & Yes \\
\hline & C11 & Easy-to-Repair & 0.5117 & 0.6327 & 0.7374 & 0.6273 & - \\
\hline \multirow{7}{*}{ Employee Performance } & $\mathrm{C} 12$ & Employee Availability & 0.6043 & 0.7279 & 0.8365 & 0.7229 & - \\
\hline & $\mathrm{C} 13$ & Employee Accuracy & 0.6252 & 0.7489 & 0.8602 & 0.7448 & - \\
\hline & $\mathrm{C} 14$ & Employee Consistency & 0.5808 & 0.7042 & 0.8159 & 0.7003 & - \\
\hline & $\mathrm{C} 15$ & Employee Productivity & 0.6676 & 0.7916 & 0.887 & 0.7821 & Yes \\
\hline & C16 & Knowledge and Skill & 0.6703 & 0.7943 & 0.8978 & 0.7875 & Yes \\
\hline & $\mathrm{C} 17$ & Employee Satisfaction & 0.6602 & 0.784 & 0.8717 & 0.7720 & Yes \\
\hline & $\mathrm{C} 18$ & Motivation and Commitment & 0.6804 & 0.8043 & 0.8864 & 0.7904 & Yes \\
\hline \multirow{8}{*}{ User-Centered Product } & C19 & Product Safety & 0.7502 & 0.8744 & 0.9334 & 0.8527 & yes \\
\hline & $\mathrm{C} 20$ & Product Reliability & 0.6769 & 0.8008 & 0.8894 & 0.7890 & - \\
\hline & $\mathrm{C} 21$ & Product Serviceability & 0.7061 & 0.8302 & 0.9189 & 0.8184 & Yes \\
\hline & $\mathrm{C} 22$ & Product Quality & 0.7076 & 0.8318 & 0.9193 & 0.8196 & Yes \\
\hline & $\mathrm{C} 23$ & Product Usability & 0.7032 & 0.8274 & 0.9228 & 0.8178 & Yes \\
\hline & $\mathrm{C} 24$ & Product Price & 0.6106 & 0.7325 & 0.8366 & 0.7266 & - \\
\hline & $\mathrm{C} 25$ & User Satisfaction & 0.7316 & 0.8559 & 0.9435 & 0.8437 & Yes \\
\hline & C26 & User Experience & 0.6805 & 0.8039 & 0.907 & 0.7971 & - \\
\hline \multirow{5}{*}{ Resource-Efficient Product } & $\mathrm{C} 27$ & Material Productivity & 0.6579 & 0.7818 & 0.8776 & 0.7724 & Yes \\
\hline & C28 & Material Quality & 0.6485 & 0.7724 & 0.8728 & 0.7646 & Yes \\
\hline & $\mathrm{C} 29$ & Material Cost & 0.6275 & 0.7496 & 0.8498 & 0.7423 & \\
\hline & C30 & Energy Utilization & 0.6694 & 0.7933 & 0.8898 & 0.7842 & Yes \\
\hline & $\mathrm{C} 31$ & Water Utilization & 0.6124 & 0.736 & 0.8436 & 0.7307 & - \\
\hline \multirow{3}{*}{ Valuable Resources } & C32 & Reusable Material & 0.6899 & 0.8126 & 0.8919 & 0.7981 & Yes \\
\hline & $\mathrm{C} 33$ & Recyclable Material & 0.6805 & 0.803 & 0.8776 & 0.7870 & Yes \\
\hline & $\mathrm{C} 34$ & Re-manufacturability of Material & 0.6572 & 0.7796 & 0.8745 & 0.7704 & - \\
\hline \multirow{3}{*}{ Wastes } & C35 & Hazardous Liquid Waste & 0.7697 & 0.893 & 0.9426 & 0.8684 & Yes \\
\hline & $\mathrm{C} 36$ & Hazardous Solid Waste & 0.71 & 0.8328 & 0.9068 & 0.8165 & - \\
\hline & $\mathrm{C} 37$ & Biodegradable Waste & 0.6946 & 0.8158 & 0.8896 & 0.8000 & - \\
\hline \multirow{3}{*}{ Emissions } & C38 & Greenhouse Gases (GHG) & 0.6672 & 0.7911 & 0.8868 & 0.7817 & - \\
\hline & C39 & Liquid Particulate Emission & 0.695 & 0.8181 & 0.9011 & 0.8047 & Yes \\
\hline & $\mathrm{C} 40$ & Solid Particulate Emission & 0.6926 & 0.8166 & 0.9049 & 0.8047 & Yes \\
\hline
\end{tabular}


From the social dimension (employee-centered products):

- Occupational safety and health: Of the six factors, four were selected as high-priority factors. Workplace accidents had the highest score of 0.7784 , followed by working conditions (with a score of 0.7781 ), psychological workload, and physiological workload.

- Simplicity of production and maintenance: Of the five factors, three were selected as high-priority factors. Easy-to-inspect and -test had the highest importance, with a score of 0.7252 , followed by easy-to-assemble and easy-to-manufacture.

- Employee performance: From the total employee performance category, motivation and commitment (0.7904), knowledge and skill (0.7875), employee productivity, and employee satisfaction needed to be prioritized in sustainability performance improvement implementation practice.

From the economic dimension (user-centered and resource efficient products):

- User-centered product: Of the eight factors, five were selected as high-priority factors. Product safety had the highest score of 0.8527 , followed by user satisfaction (0.8437), product quality, product serviceability, and product usability.

- Resource efficient product: Energy utilization had the highest score of 0.7842 , followed by material productivity (0.7724) and material quality. All required appropriate emphasis from the total factor in the specified category.

From the environmental dimension (end-of-life of product):

- Valuable resource: Reusable material, with a score of 0.7981 , and recyclable material, with a score 0.7870 , required prioritization for improvement of sustainability practice.

- Wastes: Hazardous liquid waste had the highest importance level for sustainability, with a score of 0.8684 .

- Emissions: liquid particulate emissions, and solid particulate emissions required priority.

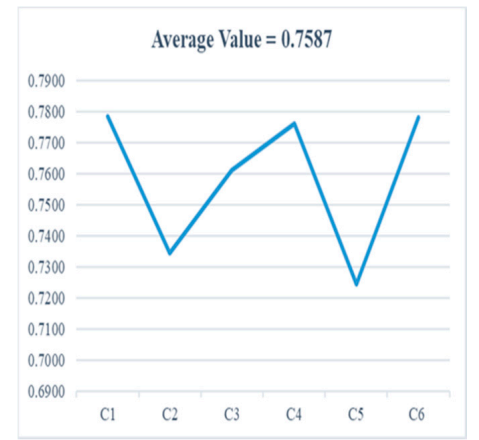

(a)

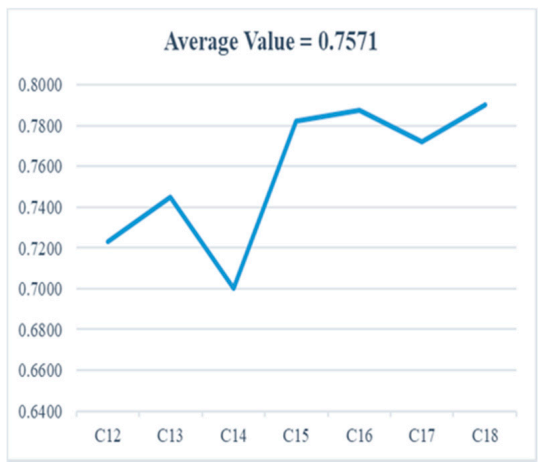

(c)

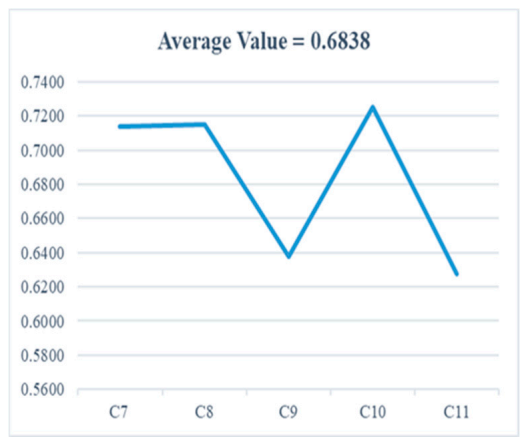

(b)

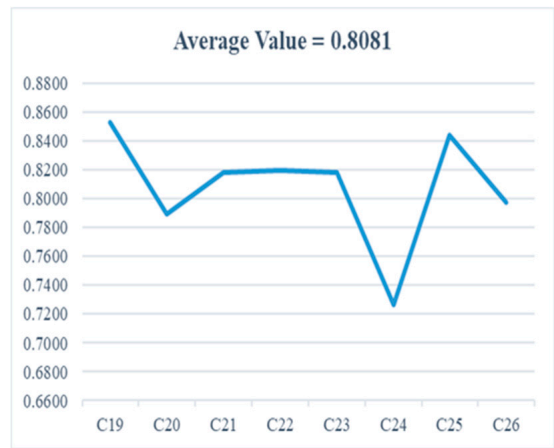

(d)

Figure 6. Cont. 


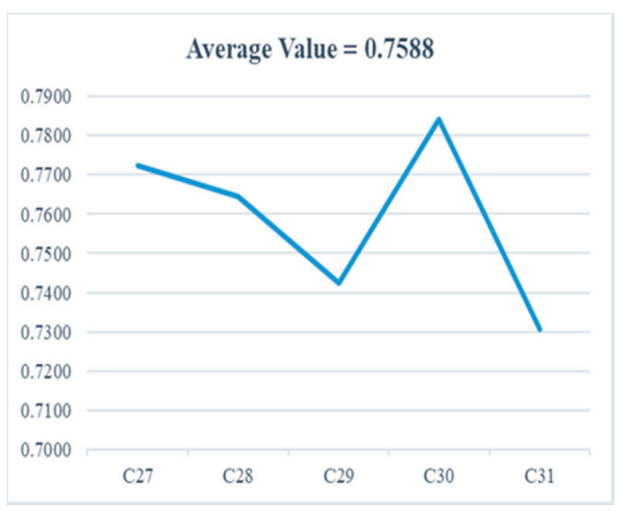

(e)

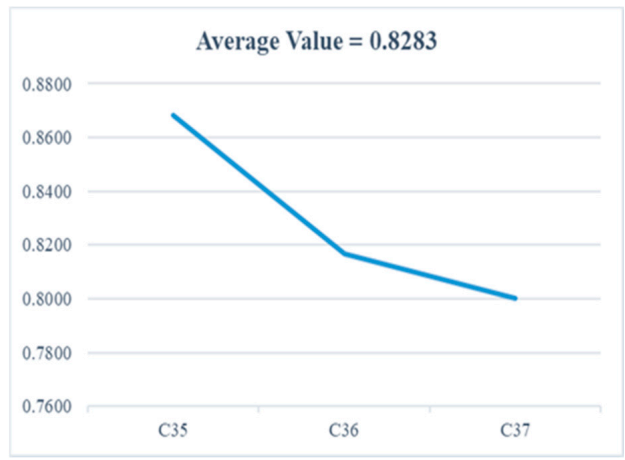

(g)

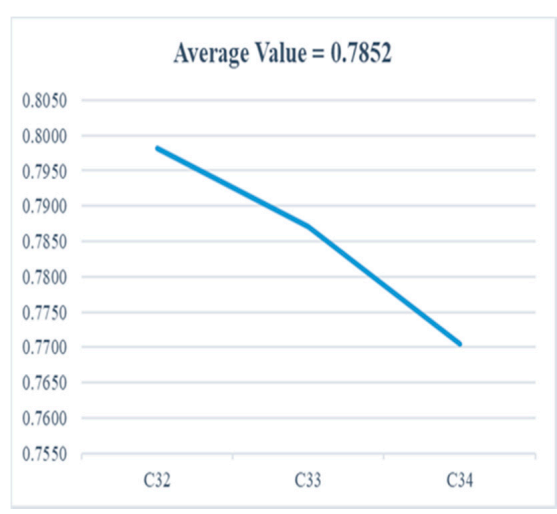

(f)

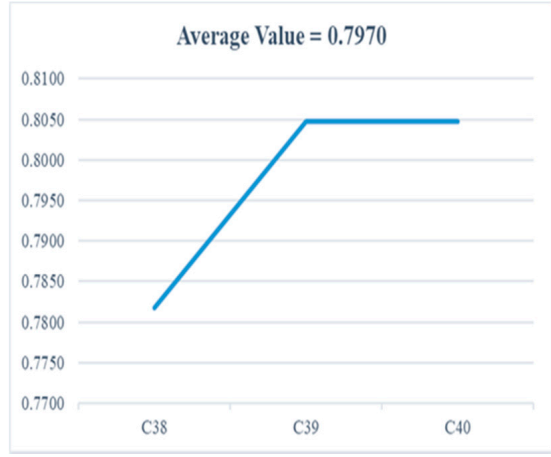

(h)

Figure 6. Line plots of combined group opinions on the $y$-axis with corresponding factors on the $x$-axis for sustainability categories: (a) occupational health and safety; (b) simplicity of production and maintenance; (c) employee performance; (d) user-centered product; (e) resource-efficient product; (f) valuable resources; (g) waste; and (h) Emissions.

\subsection{Discussion}

As reported in the literature review, an overall manufacturing product sustainability performance evaluation requires the identification of defined factors or criteria or indicators (i.e., quantitatively or qualitatively measured) and a methodological approach for achieving a manufacturing sustainability performance value. Most previous scholars have noted that complete sustainability performance is evaluated by considering the factors under the three pillars of sustainability (economic, environmental, and social) across the product life cycle (premanufacturing, manufacturing, use, and post-use), integrating the $6 \mathrm{R}$ principles. However, many of them focused on only one or two sustainability dimensions; most covered the factors under the economics and environmental dimensions and gave less attention to the factors under the social dimension. In addition, the evaluation methods in some research were limited to incomplete product life cycles. Therefore, there is a research gap on the social dimension criteria and indicators for product sustainability and manufacturing product sustainability performance evaluation considering the whole product stage.

To overcome the under-representation of the social dimension in sustainability performance evaluation and to show the contribution of ergonomics or human factors to the transition of sustainable development, this paper presents an approach for developing a framework of ergonomics-based factors or criteria of product manufacturing sustainability evaluation. An expert-based survey method was adopted to validate the importance or effects of factors on evaluating product sustainability, and also to understand those factors in each sustainability category that require priority attention in sustainability improvement programs. In the framework development process, the factors were identified based on the interaction of humans (employees, customers, and the community) with the product across its life cycle for the achievement of economic, environmental, and social benefits of manufacturing industries and their stakeholders. 
For the identification of the factors, studies related to ergonomics and sustainable development $[1,17,21,45-47]$ were considered. Some works related to sustainability assessment tools and indicators (e.g., the report of the Organization for Economic Cooperation and Development, OECD; Global Reporting Initiative, GRI; Dow Jones Sustainability Index, DJSI) were utilized as sources of guidance, and expert suggestions were considered. In the developed framework, these factors are categorized into their respective dimensions: social (employee wellbeing), economic (user-centered and resource-efficient products) and environmental (end-of-life of product) and eight categories. The combined or aggregated effects of the factors evaluate the overall product manufacturing performance. In addition to developing a sustainability framework, the study utilized the fuzzy Delphi method to validate the importance or effects of the factors and to screen their importance levels in evaluating product manufacturing performance. This approach should help manufacturing industries to allocate their resources for those factors requiring priority to improve their product sustainability performance.

The levels of importance of each of the factors on product sustainability were decided based on the combined opinions of experts. The priority decision for each factor was made within its sustainability category because similar factors were included in the same category. For example, occupational health and safety, one of the sustainability categories under the social dimension (employee-centered product), consists of six sustainability factors. The average or threshold value for this category was 0.7587 , and workplace accidents, working conditions, psychological workload, and physiological workload require priority because their combined real scores from experts were greater than 0.7587 . In the same way, user-centered product, another sustainability category under the economic dimension (user-centered and resource efficient), comprises eight sustainability factors. The average value for this category was 0.8081 , and product safety, user satisfaction, product quality, product serviceability, and product usability demand priority.

\section{Conclusions}

Sustainability is one of the most important issues facing manufacturers today because of the scarcity of natural resources, governmental regulations, and increasing customer demand for sustainable products. To achieve sustainable product manufacturing that can satisfy these requirements and also make manufacturing industries competitive, it is important to consider a comprehensive sustainability evaluation framework that integrates sustainability pillars, the total life cycles of products, and the $6 \mathrm{R}$ principles. Ergonomics or human factors are among the different areas that contribute to sustainable product manufacturing. In this research, a framework of performance evaluation for sustainability in manufacturing industries has been studied, and ergonomics-based factors or criteria influencing the sustainability of manufactured products across its life cycle have been investigated.

The developed model of a sustainable product manufacturing framework consists of 40 ergonomicsbased factors organized into eight sustainability categories (occupational safety and health, simplicity of production and maintenance, employee performance, user-centered product, resource-efficient product, valuable resources, waste, and emissions) and three sustainability dimensions (employee wellbeing: employee-centered product; economic: user-centered and resource-efficient products; and environmental: end-of-life of product). These factors are identified based on their direct and indirect influences on the social, economic, and environmental benefits to the employee, customer, and community. In addition to identifying the factors, this study validated the importance levels of the factors for sustainable product manufacturing using the fuzzy Delphi method. The expert-based questionnaire was designed with linguistic variable alternative responses to collect the opinions of experts on the importance levels of each of the factors. After the reliability of the data was checked using Cronbach's alpha, the combined opinions of experts were determined by an algorithm comprising the degrees of importance of the experts, and the similarities and differences between the expert opinions. The overall combined opinions corresponding to the factors (i.e., all defuzzified values corresponding to factors are between 0.625 to 0.875 ) showed that all are important influential factors of sustainable product manufacturing. Moreover, the priority of the factors on the importance level was 
also investigated by comparing the defuzzified values of the factors with the threshold values set to their corresponding sustainability category. This should provide a guide for management decisions on resource allocation for each of the factors to improve the manufacturing sustainability performance.

The contribution of this research is to identify the factors that are directly and indirectly associated with the social dimension affecting the manufacture of sustainable products; it also illustrates to some extent how ergonomics or human factors contribute to sustainable manufacturing. Future research could focus on the development of appropriate methods to measure qualitatively and quantitatively the identified factors and come up with a defined product manufacturing sustainability index or value. In addition, case studies applying the developed method can be conducted to evaluate the product sustainability performance levels of manufacturing industries and explore another research direction.

Author Contributions: C.J.L. guided the design of the research work, wrote the manuscript, and supervised the research; T.C.K. reviewed the manuscript, facilitated the data collection, and provided publication support; and T.T.B. conducted the literature review, processed and analyzed the data, and wrote the manuscript.

Funding: This research received no external funding.

Acknowledgments: The authors would like to thank to Azemeraw Tadesse Mengistu for his partial contribution towards an earlier development of the work, following Chiuhsiang Joe Lin's ideas and guidance.

Conflicts of Interest: The authors declare no conflict of interest.

\section{References}

1. Haslam, R.; Waterson, P. Ergonomics and Sustainability. Ergonomics 2013, 56, 343-347. [CrossRef] [PubMed]

2. Huang, A.; Badurdeen, F. Sustainable Manufacturing Performance Evaluation: Integrating Product and Process Metrics for Systems Level Assessment. Procedia Manuf. 2017, 8, 563-570. [CrossRef]

3. Sabaghi, M.; Mascle, C.; Baptiste, P.; Rostamzadeh, R. Sustainability assessment using fuzzy-inference technique (SAFT): A methodology toward green products. Expert Syst. Appl. 2016, 56, 69-79. [CrossRef]

4. Shuaib, M.; Seevers, D.; Zhang, X.; Badurdeen, F.; Rouch, K.E.; Jawahir, I.S. Product Sustainability Index (ProdSI) A Metrics-based Framework to Evaluate the Total Life Cycle Sustainability of Manufactured Products. J. Ind. Ecol. 2014, 18, 491-507. [CrossRef]

5. Zhang, X.; Lu, T.; Shuaib, M.; Rotella, G.; Huang, A.; Feng, S.C.; Rouch, K.; Badurdeen, F.; Jawahir, I.S. A Metrics-Based Methodology for Establishing Product Sustainability Index (ProdSI) for Manufactured Products. In Leveraging Technology for a Sustainable World; Springer: Berlin/Heidelberg, Germany, 2012; pp. 435-441.

6. UNs Sustainable Development Goals: 17 Goals to Transform Our World. Available online: https://www.un. org/development/desa/disabilities/envision2030.html (accessed on 17 June 2019).

7. WCED. Report of the World Commission on Environment and Development: Our Common Future; Oxford University Press: Oxford, UK, 1987.

8. Huang, A. A Framework and Metrics for Sustainable Manufacturing Performance Evaluation at the Production Line, Plant and Enterprise Levels. Ph.D. Thesis, University of Kentucky, Lexington, KY, USA, 2017.

9. Badurdeen, F.; Jawahir, I.S.; Rouch, K.E. A Metrics-Based Evaluation of Sustainable Manufacturing at Product and Process Levels. In Reference Module in Earth Systems and Environmental Sciences; Elsevier: Amsterdam, The Netherlands, 2017.

10. Garetti, M.; Taisch, M. Sustainable manufacturing: Trends and research challenges. Prod. Plan. Control 2012, 23, 83-104. [CrossRef]

11. Gupta, A.; Jayal, A.D.; Chimienti, M.; Jawahir, I.S. A Total Life-Cycle Approach towards Developing Product Metrics for Sustainable Manufacturing; Springer: Berlin/Heidelberg, Germany, 2011; pp. 240-245.

12. Latif, H.H.; Gopalakrishnan, B.; Nimbarte, A.; Currie, K. Sustainability index development for manufacturing industry. Sustain. Energy Technol. Assess. 2017, 24, 82-95. [CrossRef]

13. Zarte, M.; Pechmann, A.; Nunes, I.L. Indicator framework for sustainable production planning and controlling. Int. J. Sustain. Eng. 2019, 12, 149-158. [CrossRef]

14. Venugopal, V.; Saleeshya, P.G. Manufacturing system sustainability through lean and agile initiatives. Int. J. Sustain. Eng. 2019, 12, 149-158. [CrossRef] 
15. Fechete, F.; Nedelcu, A. Performance Management Assessment Model for Sustainable Development. Sustainability 2019, 11, 2779. [CrossRef]

16. Husgafvel, R.; Pajunen, N.; Virtanen, K.; Paavola, I.-L.; Päällysaho, M.; Inkinen, V.; Heiskanen, K.; Dahl, O.; Ekroos, A. Social Sustainability Performance Indicators-Experiences from Process Industry. Int. J. Sustain. Eng. 2014, 8, 14-25. [CrossRef]

17. Cao, Y.; Wang, S.; Lili, Y.; Zhou, J. A Social Sustainability Assessment Model for Manufacturing Systems Based on Ergonomics and Fuzzy Inference System. In International Conference on Sustainable Design and Manufacturing; Springer: Cham, Switzerland, 2016; pp. 639-648.

18. Sutherland, J.W.; Richter, J.S.; Hutchins, M.J.; Dornfeld, D.; Dzombak, R.; Mangold, J.; Robinson, S.; Hauschild, M.Z.; Bonou, A.; Schönsleben, P.; et al. The role of manufacturing in affecting the social dimension of sustainability. CIRP Ann. 2016, 65, 689-712. [CrossRef]

19. Papetti, A.; Gregori, F.; Pandolfi, M.; Peruzzini, M.; Germani, M. IoT to Enable Social Sustainability in Manufacturing Systems. In Transdisciplinary Engineering Methods for Social Innovation of Industry 4.0, Proceedings of the 25th ISPE Inc. International Conference on Transdisciplinary Engineering, 3-6 July 2018; IOS Press: Amsterdam, The Netherlands, 2018.

20. Meyer, F.; Eweje, G.; Tappin, D. Ergonomics as a tool to improve the sustainability of the workforce. Work 2017, 57, 339-350. [CrossRef] [PubMed]

21. Radjiyev, A.; Qiu, H.; Xiong, S.; Nam, K. Ergonomics and sustainable development in the past two decades (1992-2011): Research trends and how ergonomics can contribute to sustainable development. Appl. Ergon. 2015, 46, 67-75. [CrossRef] [PubMed]

22. Martin, K.; Legg, S.; Brown, C. Designing for sustainability: Ergonomics-Carpe diem. Ergonomics 2013, 56, 365-388. [CrossRef] [PubMed]

23. Ryan, B.; Wilson, J.R. Ergonomics in the development and implementation of organisational strategy for sustainability. Ergonomics 2013, 56, 541-555. [CrossRef] [PubMed]

24. Eslami, Y.; Dassisti, M.; Panetto, H.; Lezoche, M. Sustainability assessment of manufacturing organizations based on indicator sets: A formal concept analysis. In Lecture Notes in Computer Science (Including Subseries Lecture Notes in Artificial Intelligence and Lecture Notes in Bioinformatics); Springer: Cham, Switzerland, 2019; Volume 11231 LNCS, pp. 36-44.

25. Fiksel, J.; McDaniel, J.; Spitzley, D. Measuring Product Sustainability. J. Sustain. Prod. Des. 1998, 1-16. Available online: citeseerx.ist.psu.edu/viewdoc/download?doi=10.1.1.627.8635\&rep=rep1\&type=pdf (accessed on 10 September 2019).

26. Schuch Bork, C.A.; de Souza, J.F.; de Oliveira Gomes, J.; Venancio Pappetti Canhete, V.; De Barba, D.J. Methodological tools for assessing the sustainability index (SI) of industrial production processes. Int. J. Adv. Manuf. Technol. 2016, 87, 1313-1325. [CrossRef]

27. Singh, S.; Olugu, E.U.; Fallahpour, A. Fuzzy-based sustainable manufacturing assessment model for SMEs. Clean Technol. Environ. Policy 2014, 16, 847-860. [CrossRef]

28. Veleva, V.; Ellenbecker, M. Indicators of sustainable production: Framework and methodology. J. Clean. Prod. 2001, 9, 519-549. [CrossRef]

29. Elkington, J. Cannibals with Forks: The Triple Bottom Line of 21st Century Business; Capstone: Oxford, UK, 1997.

30. McKenzie, S. Social Sustainability: Towards Some Definitions; Hawke Research Institute, University of South Australia: Magill, Australia, 2004.

31. Ocampo, L.A. A hierarchical framework for index computation in sustainable manufacturing. Adv. Prod. Eng. Manag. 2015, 10, 40-50. [CrossRef]

32. Joung, C.B.; Carrell, J.; Sarkar, P.; Feng, S.C. Categorization of indicators for sustainable manufacturing. Ecol. Indic. 2013, 24, 148-157. [CrossRef]

33. Salvado, M.F.; Azevedo, S.; Matias, J.; Ferreira, L. Proposal of a Sustainability Index for the Automotive Industry. Sustainability 2015, 7, 2113-2144. [CrossRef]

34. Xu, Y.; Wang, H. Optimal Weight Determination and Consensus Formation under Fuzzy Linguistic Environment. Procedia Comput. Sci. 2013, 17, 482-489. [CrossRef]

35. Chen, D.; Chu, X.; Yang, X.; Sun, X.; Li, Y.; Su, Y. PSS solution evaluation considering sustainability under hybrid uncertain environments. Expert Syst. Appl. 2015, 42, 5822-5838. [CrossRef]

36. Zhang, L.; Xu, X.; Tao, L. Some similarity measures for triangular fuzzy number and their applications in multiple criteria group decision-making. J. Appl. Math. 2013, 2013, 538261. [CrossRef] 
37. Saffie, N.A.M.; Shukor, N.M.; Rasmani, K.A. Fuzzy Delphi method: Issues and challenges. In Proceedings of the 2016 International Conference on Logistics, Informatics and Service Sciences (LISS), Sydney, NSW, Australia, 24-27 July 2016; pp. 1-7.

38. Lee, H.S. Optimal consensus of fuzzy opinions under group decision making environment. Fuzzy Sets Syst. 2002, 132, 303-315. [CrossRef]

39. Hsu, H.M.; Chen, C.T. Aggregation of fuzzy opinions under group decision making. Fuzzy Sets Syst. 1996, 79, 279-285.

40. Chen, S.M. Aggregating fuzzy opinions in the group decision-making environment. Cybern. Syst. 1998, 29, 363-376. [CrossRef]

41. George, B.; Maria, B. Fuzzy Set, Fuzzy Logic, Applications: Advances in Fuzzy Systems-Applications and Theory; World Scientific Publishing CO. Pte. Ltd.: Singapore, 1995; Volume 5.

42. Lu, C.; Lan, J.; Wang, Z. Aggregation of fuzzy opinions under group decision-making based on similarity and distance. J. Syst. Sci. Complex. 2006, 19, 63-71. [CrossRef]

43. Sanchez-Lezama, A.P.; Cavazos-Arroyo, J.; Albavera-Hernandez, C. Applying the Fuzzy Delphi Method for determining socio-ecological factors that influence adherence to mammography screening in rural areas of Mexico. Cadernos Saúde Pública 2014, 30, 245-258. [CrossRef] [PubMed]

44. Pour, A.D.F. The Application of Fuzzy Delphi Method (FDM) For Evaluating The Factors Affecting Sustainable Tourism in Order To Develop A Model For Sustanable Tourism. IOSR J. Bus. Manag. IOSR-JBM 2016, 18, 23-29. [CrossRef]

45. Legg, S.; Brown, C. Achieving Transition to Sustainability: Lessons from Human Factors and Ergonomics. In Proceedings of the 4th International Conference on Sustainability Engineering and Science, Auckland, New Zealand, 30 November-3 December 2010.

46. Qureshi, M.I.; Rasiah, R.A.; Al-Ghazali, B.M.; Haider, M.; Jambari, H.; Iswan; Sasmoko. Modeling Work Practices under Socio-Technical Systems for Sustainable Manufacturing Performance. Sustainability 2019, 11, 4294. [CrossRef]

47. Kishawy, H.A.; Hegab, H.; Saad, E. Design for Sustainable Manufacturing: Approach, Implementation, and Assessment. Sustainability 2018, 10, 3604. [CrossRef]

(C) 2019 by the authors. Licensee MDPI, Basel, Switzerland. This article is an open access article distributed under the terms and conditions of the Creative Commons Attribution (CC BY) license (http://creativecommons.org/licenses/by/4.0/). 